\title{
A BACIA DO ITAJAÍ-AÇU PEDE AJUDA: REAÇÕES AO APELO
}

\author{
Eunice Sueli Nodari ${ }^{1}$
}

\section{Introdução}

O crescimento urbano em cidades médias e grandes que são cruzadas por rios, ou tem rios as suas margens, tem como uma das suas consequências a poluição dos mesmos. As causas desta poluição decorrem da presença nos rios de esgotos não tratados, produtos químicos das indústrias e da agricultura e o lixo jogado pela população, entre outros. Desta forma, rios que nascem com água pura e cristalina, com o passar dos anos se transformam em lixões a céu aberto, principalmente nos trechos de seus leitos após o recebimento dos produtos acima mencionados.

Geralmente quando este tema é abordado são lembrados no Brasil os rios Tietê em São Paulo ${ }^{2}$ e a própria Baía da Guanabara. Entretanto, vários rios dos Estados do Rio Grande do Sul e de Santa Catarina enfrentam problemas similares. Como exemplo podemos citar os três rios da Região Metropolitana de Porto Alegre que estão na quarta, quinta e oitava posições na lista dos mais poluídos do Brasil, segundo dados do Índice de Desenvolvimento Sustentável do Instituto Brasileiro de Geografia e Estatística (IBGE). Os rios dos Sinos, Gravataí e Caí têm em comum a água escura e muita sujeira.

No caso de Santa Catarina os rios que atravessam as cidades e em época de chuvas intensas causam desde alagamentos até grandes enchentes, trazendo com eles todo o tipo de lixo descartado nas partes urbanas e rurais à montante. A base para 0 nosso estudo é a bacia do rio Itajaí-Açu, que é um dos maiores exemplos, pois recebe dejetos agrícolas e industriais, lixo doméstico e esgoto sem tratamento, que são uma ameaça a fauna e a flora concentradas nas ilhas fluviais do Itajaí-Açu. No entanto, este quadro de ameaças mencionadas está sendo alterado de forma positiva devido a ações de cunho socioambiental nas últimas décadas.

\footnotetext{
${ }^{1}$ Universidade Federal de Santa Catarina, Brasil. Email: eunice.nodari@ufsc.br ORCID id : https://orcid.org/0000-0001-5953-649X

${ }^{2}$ Para maiores detalhes ver: JORGE, Janes. Tietê - o rio que a cidade perdeu: São Paulo, 1890-1940. São Paulo: Alameda, 2006.
} 
O presente artigo está dividido da seguinte forma: histórico e localização da bacia do rio Itajaí-Açu; poluição dos rios da bacia; exemplos de ações para diminuição dos problemas, sendo que estas estão divididas em ações de empresas, da população com ajuda da imprensa e organizações sociais. A metodologia empregada foi a análise de fontes dos periódicos estaduais e regionais, além de relatórios e material iconográfico, especialmente fotografias divulgadas na imprensa no decorrer dos anos. A análise destas fontes confrontadas com dados de trabalhos já publicados propiciará um perfil histórico das iniciativas tomadas no decorrer das duas últimas décadas.

\section{Contextualização}

A contaminação da água está diretamente ligada ao grau de contaminação e poluição em nosso meio ambiente. Como resultado, o ciclo hidrológico pode ser afetado em vários níveis. Depois que a poluição do ar é liberada pelo vento e pela chuva ela é levada sobre a terra antes de correr para dentro dos rios, aquíferos subterrâneos e lagos. Como a água potável e de irrigação vêm de águas de superfície e subterrâneas qualquer produto químico ou dejetos industriais e agroprecuários utilizados pode contaminar o abastecimento de água e os organismos aquáticos. Feita esta breve introdução sobre a contaminação da água, vamos ao objetivo do presente artigo.

\section{O Vale do rio Itajaí-Açu e a sua Bacia Hidrográfica}

O Vale do Rio Itajaí-Açu, situado no nordeste do Estado de Santa Catarina, abriga a maior bacia hidrográfica do Estado (Figura1). A região conta com cerca de um milhão de habitantes, sendo que $76 \%$ concentram-se nos centros urbanos. A região apresenta grande importância socioeconômica abrigando além das cidades portuárias de Itajaí e Navegantes, polos industriais como Blumenau, Brusque e Rio do Sul. Este reconhecimento no setor de desenvolvimento econômico traz consigo, por falta de cuidados, os resultados nefastos desse progresso que é a poluição dos rios da bacia.

A Bacia do Rio Itajaí-Açu compreende uma área total de $15.500 \mathrm{~km}^{2}$, o que corresponde a 16,15\% do território catarinense, abrangendo 52 municípios. A Bacia tem como limites geográficos os estabelecidos pelas configurações fisiográficas da Serra Geral e da Serra dos Espigões a Oeste, das Serras da Boa Vista, dos Faxinais e do 
Tijucas ao sul, e das Serras da Moema e do Jaraguá ao norte, e pelo Oceano Atlântico a leste. A Bacia do Itajaí-Açu é dividida em três regiões conhecidas como Alto Vale, Médio Vale e Baixo Vale.

O maior curso d'água da bacia é o Rio Itajaí-Açu, formado pela junção dos Rios Itajaí do Oeste e Itajaí do Sul, no município de Rio do Sul. O Rio Itajaí-Açu recebe como principais afluentes: o Rio Itajaí do Norte em Ibirama, o Rio Benedito em Indaial, o Rio Luiz Alves em lhota e o Rio Itajaí Mirim, que aporta na bacia estuaria a $9 \mathrm{~km}$ da barra, em Itajaí (Frank; Sevegnani, 2009: 27). A bacia do Itajaí se divide em 7 subbacias hidrográficas principais que levam o nome do principal rio existente.

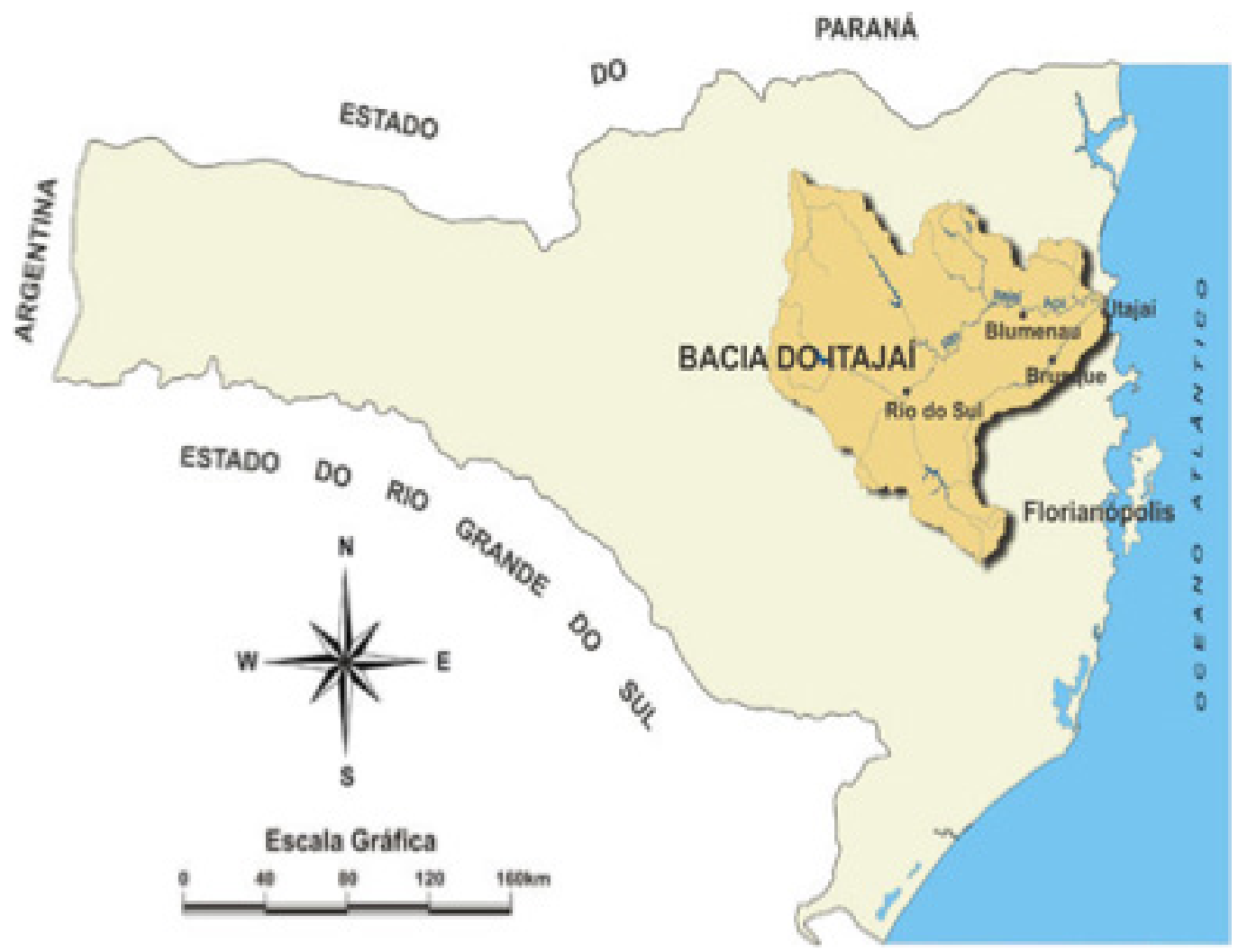

Figura 1. Mapa de Santa Catarina com destaque da localização da Bacia do Itajaí-Açu. Fonte: Comitê do Itajaí, 2010.

O Rio Itajaí-Açu aparece frequentemente em diferentes mídias em nível nacional, estadual e regional devido às grandes enchentes que ocorrem com muita frequência. Como exemplo podemos citar a cidade de Blumenau que desde a sua fundação em 1850 foi afetada pelas enchentes do Rio Itajaí-Açu. A vulnerabilidade da região se deu, principalmente, a junção de dois fatores: a ação humana e a prédisponibilidade física a eventos naturais. A ocupação de grande parte da região no Vale 
do Itajaí-Açu seguiu o modelo alemão denominado Stadtplatz (lugar da cidade), baseado no assentamento da população seguindo o curso do rio. Citando como exemplo a cidade de Blumenau o modelo ditou "a ocupação urbana da cidade, que se manteve às margens do rio Itajaí-Açu, levando ao desmatamento da mata ciliar, ocupação indevida nas encostas, entre outros fatores que levaram ao agravamento das enchentes ao longo dos anos" (Paula; Espindola; Nodari; 2014: 202).

As enchentes se tornaram recorrentes no decorrer do século XX, algumas com maiores danos que outras. Dentre as maiores enchentes que ocorreram na Bacia do Rio Itajaí-Açu a de $2008^{3}$, se constituiu em um dos maiores desastres socioambientais da região. Segundo Mattedi et al "na noite do dia 22 de novembro de 2008, após um extenso período de chuvas constantes que resultou na saturação do solo, o vale do Itajaí foi assolado pela maior tragédia ambiental da sua história" (Mattedi, M.A.: Frank B.; Sevegnani L.; Bohn, N., 2009: 16). De acordo com Ávila e Mattedi os dados estatísticos registraram que 25 mil pessoas foram alojadas em casas de vizinhos, parentes e amigos, 2.383 foram feridas e 24 perderam a vida, na cidade de Blumenau (2017: 191). Isso sem mencionar todos os danos materiais. O desastre de 2008, foi avassalador para o Estado de Santa Catarina. Ainda de acordo com os mesmos autores, no total 14 municípios decretaram estado de calamidade pública, e 63, situações de emergência. As consequências mais funestas ocorreram na região do Vale (Avila; Mattedi 2017: 191). É importante salientar que, diferentemente do que é propagado pela mídia e também passa no imaginário do governo e da população, “os desastres não são somente um problema para o desenvolvimento da região, mas, principalmente, uma consequência do próprio desenvolvimento" (Mattedi, M.A.: Frank B.; Sevegnani L.; Bohn, N., 2009:17).

$\mathrm{Na}$ análise de especialistas sobre o tema,

A destruição foi desencadeada, de um lado, pela sobrecarga da capacidade assimilativa e regenerativa do ambiente natural e, de outro, pela incapacidade cognitiva de identificar as causas e pela incapacidade política de formular e implementar estratégias de previsão e preparação para conviver com o problema. $\mathrm{Na}$ verdade, aos fatores já mencionados, soma-se o processo de gestão autoritário de formulação e implantação de políticas públicas, que excluiu sistematicamente a participação da sociedade organizada (Mattedi, M.A.: Frank B.; Sevegnani L.; Bohn, N., 2009: 17).

\footnotetext{
${ }^{3}$ Para maiores detalhes sobre a enchente de 2008 e seus efeitos em Blumenau ver: SILVA, R. A. C. Águas de novembro: estudo antropológico sobre memória e vitimização de grupos sociais citadinos e ação da Defesa Civil na experiência de calamidade pública por desastre ambiental (Blumenau, Brasil). 2013. Tese (Doutorado) - Universidade Federal do Rio Grande do Sul, Porto Alegre, 2013.
} 
O rio que atravessa a cidade ou a rodeia muitas vezes é visto como um inimigo em momentos de desastres. Todavia, em tempos menos turbulentos, muitas vezes, a população esquece desse rio que é o que abastece de água as cidades e serve de lazer entre outros aspectos. As enchentes servem como um bom exemplo, pois deixam à mostra, de forma clara à falta desta preocupação da população com o rio, como pode ser observado na Figura 2.

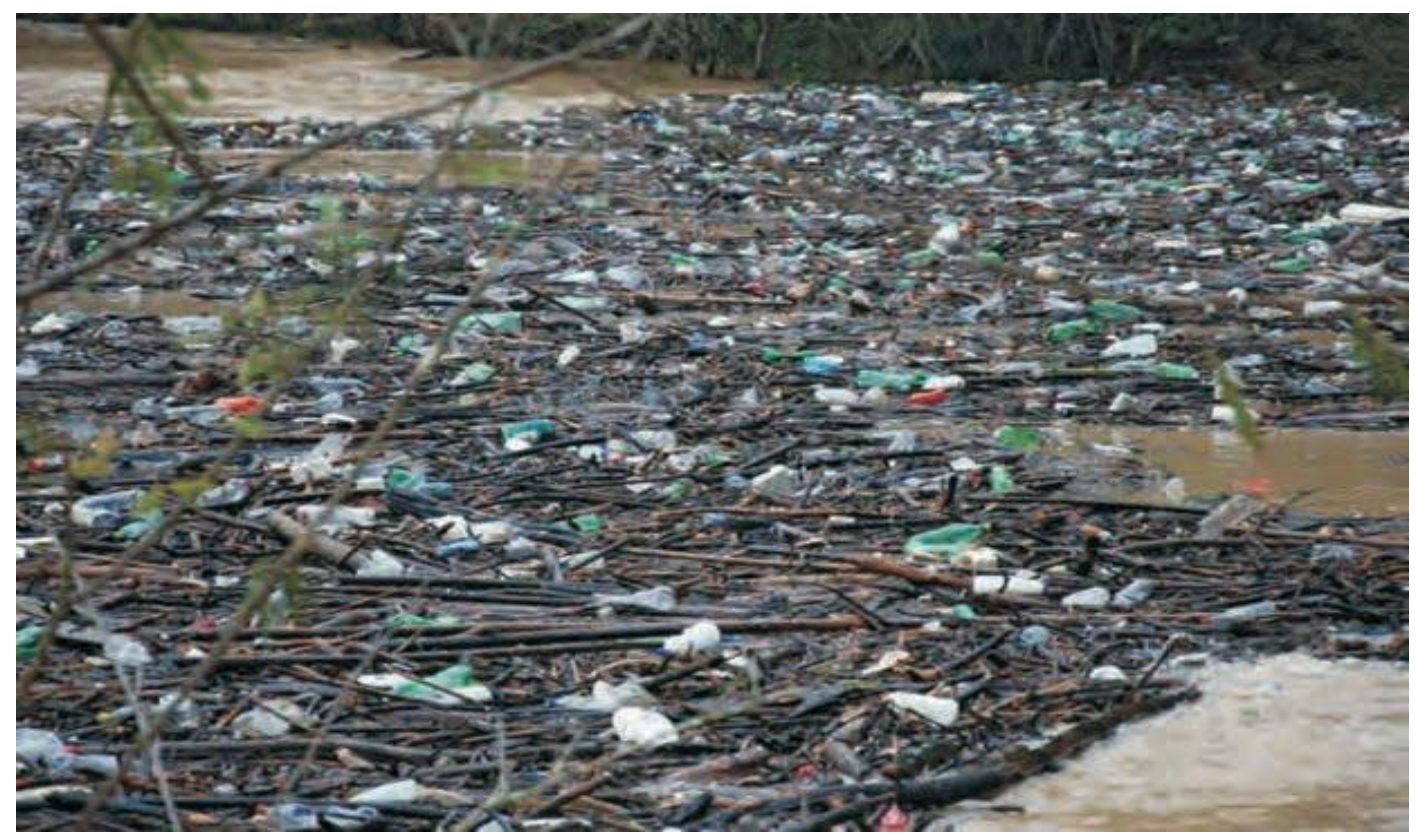

Figura 2. "Tapetão" de lixo que se forma nas imediações da Usina durante as cheias. Fonte: Boletim Técnico n. 4. - Imagens de Jair Fabiciack. Disponível em: http://docplayer.com.br/59514800-4-0-itaja-iacu-bole-tim-tecnic-o-o-grand-e-rio-pede-socorr-o-acionistas-c-a-m-p-a-n-h-a.html - acesso em 13.04.2020

Mesmo que as enchentes tragam à tona o lixo acumulado nas cidades e na zona rural, as indústrias são consideradas uma das maiores poluidoras da Bacia, pois os danos são constantes. A indústria têxtil é a principal atividade do Vale do Itajaí, que é o maior produtor do segmento na América Latina. Porém, esse setor causa grandes impactos ambientais, por causa do consumo de água e tratamento de efluentes, energia, produtos químicos e desperdício nos processos de produção.

As indústrias de transformação na macrorregião do Vale do Itajaí no ano de 2011 compunham cerca de 11.886 unidades industriais entre micro empresas, pequenas, médias e grandes. (Santa Catarina em números, 2013:52). Segundo Menezes, as indústrias do ramo têxtil "tem aproximadamente 6.500 empresas de diferentes dimensões e empregavam cerca de 124 mil trabalhadores" (Menezes, 2009: 114). Ainda segundo a autora, 
o Estado é responsável por $90 \%$ da produção nacional de roupa de cama, mesa e banho, bem como por $80 \%$ das malhas produzidas no País. As principais indústrias do setor são a Cia Hering (Blumenau), a Marisol S/A (Jaraguá do Sul), a Teka (Blumenau), a Circulo S.A. (Gaspar), a Buettner S/A (Brusque), a Cremer S/A (Blumenau), a Karsten S/A (Blumenau), a Altenburg (Blumenau), a Cia. Fabril Lepper (Joinville), a Haco Etiquetas Ltda. (Blumenau), a Buddemeyer S/A (São Bento do Sul), a Dudalina (Blumenau), a Kyly Indústria Têxtil Ltda. (Pomerode), a Fiação São Bento S/A (São Bento do Sul) e a Malharia Brandilli Ltda. (Apiúna). Esse dinamismo socioeconômico tem acarretado inúmeros problemas de contaminação dos recursos hídricos sobretudo nas Bacias dos rios Itapocu e ItajaíAçu, em consequência do escoamento descontrolado de sobras de corantes oriundos das tinturarias, lavanderias e estamparias. (Menezes, 2009: 114)

Poluição da Bacia: Notícias da imprensa e expedições

Como já foi mencionado acima a poluição dos rios e riachos que compõem a bacia do Itajaí aparecem na mídia e também em expedições através do Rio Itajaí-Açu. Como primeiro exemplo, mencionamos o trabalho de campo que foi realizado por uma equipe organizada pela Usina Salto do Pilão,

Em função do grande volume de lixo constatado nas grades da Tomada d'água da Usina Salto Pilão, em Lontras (notadamente, depois da enchente de setembro de 2011, e, em menor volume, nas cheias de 2013) foi planejada, organizada e realizada uma expedição pelas águas dos rios Itajaí do Sul, Itajaí do Oeste e Itajaí-Açu, com o objetivo de entender como o Grande Rio nasce, qual o processo de poluição e degradação ao longo de seu leito e como esse grande curso d'água interfere na vida de milhares de pessoas e dezenas de municípios (Boletim Técnico n. 4, 2014: 9).

Um dos integrantes da expedição foi o jornalista Jair Fabiciack e, segundo o mesmo, no referido trabalho de campo buscaram retratar as condições num trecho de 190 quilômetros do Itajaí-Açu, na região do Alto Vale. De acordo com Fabiciack e Nau, praticamente desde as nascentes foi constatado que "lixo, em particular, é a mostra mais nefasta de agressão." E acrescentam: "Garrafas plásticas contendo restos de refrigerante e de veneno usado na atividade agropastoril, carcaças de móveis e de geladeiras, pneus, isopor, calçados, animais mortos, madeira e galharia compõem um mosaico que pode ser observado navegando pelo rio Itajaí” (Fabiciack; Nau, 2012: 2).

Os flagrantes encontrados pela expedição, podem ser vistos em inúmeras fotografias, onde fica evidente a falta de preocupação com os rios por parte da população urbana e rural e das indústrias, um exemplo pode ser observado na Figura 3, onde aparecem embalagens de agrotóxicos com outros objetos descartados no rio. 


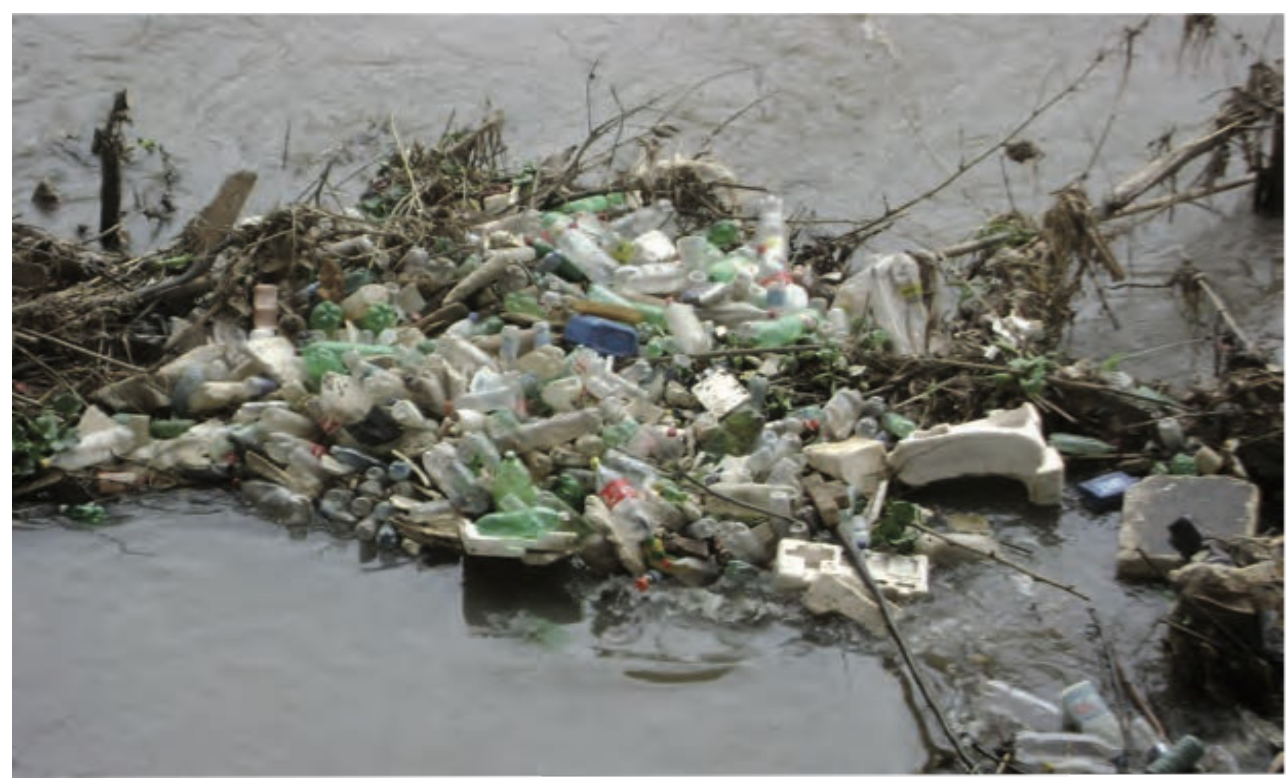

Figura 3 - Lixo provoca a contaminação na água com componentes químicos, tipo AOX Fonte- Boletim Técnico n.4 - Fotografia de Jair Fabiciack. Disponível em:

http://docplayer.com.br/59514800-4-o-itaja-i-acu-bole-tim-tecnic-o-o-grand-e-rio-pede-socorr-oacionistas-c-a-m-p-a-n-h-a.html - acesso em 13.04.2020

Segundo o relato de membros da expedição, a poluição aumenta "na medida que o rio entra em contato com áreas urbanizadas." Na Figura 4, se observa outra situação bastante comum de acordo com o Boletim, que é o lançamento direto no rio de lixo e esgoto.

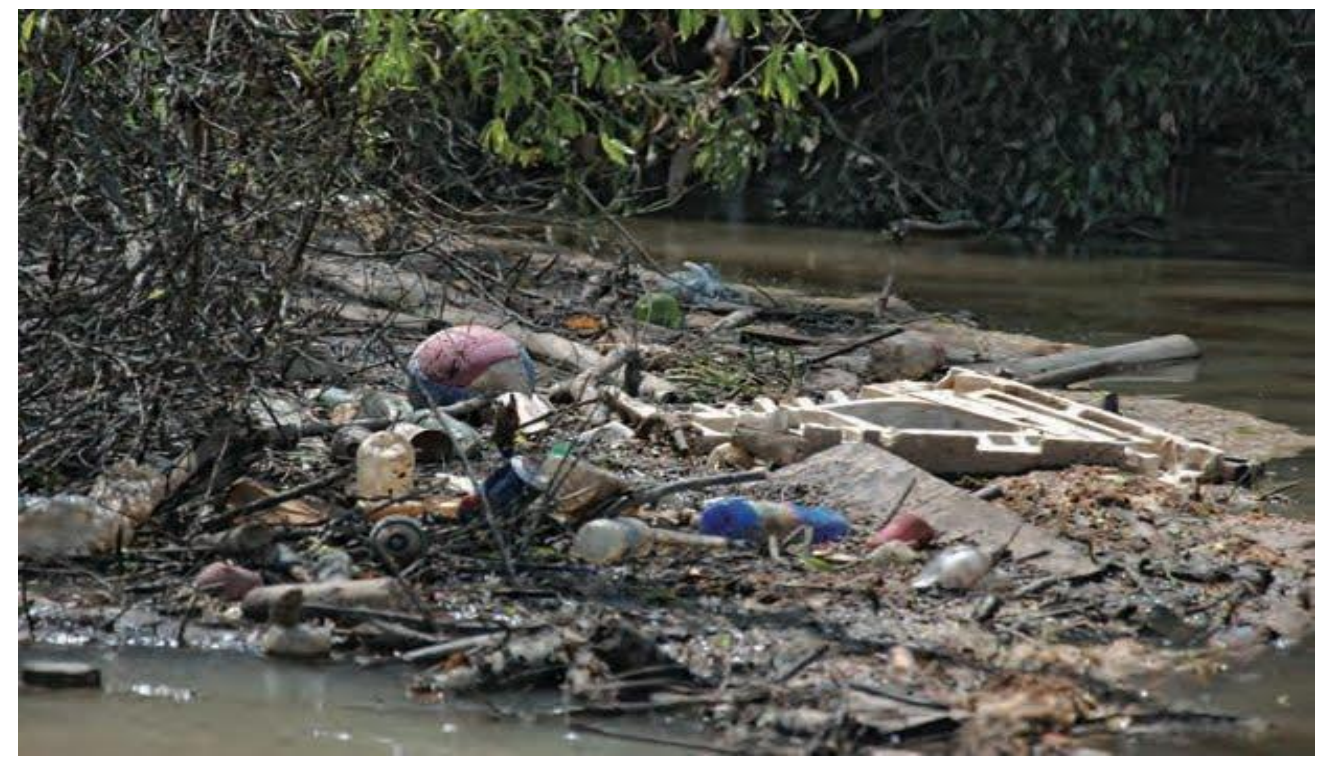

Figura 4 - Lançamento direto de lixo e esgoto acontece em toda a extensão do rio

Fonte- Boletim n.4 - Fotografia de Jair Fabiciack. Disponível em: http://docplayer.com.br/59514800-4-0itaja-i-acu-bole-tim-tecnic-o-o-grand-e-rio-pede-socorr-o-acionistas-c-a-m-p-a-n-h-a.html - Acesso em 13.04.2020 
Assim como foi constatado pela expedição acima mencionada, a imprensa local e regional também publica inúmeras reportagens mostrando a forma como o rio, muitas vezes é tratado pela população. O Jornal de Santa Catarina, em sua edição do dia 7 de junho de 2011, publicou em suas páginas:

\begin{abstract}
Dejetos agrícolas e industriais, lixo doméstico e esgoto sem tratamento ameaçam a fauna e a flora exuberantes concentradas nas ilhas fluviais do Itajaí-Açu. Desde o início, em Rio do Sul, a poluição aumenta à medida que o rio entra em contato com áreas urbanas. Nos pontos críticos, em Blumenau e Gaspar, o nível de coliformes fecais supera em 28 vezes o limite - o indicador chega a 140, quando acima de cinco já é considerado preocupante. Já os níveis de compostos químicos conhecidos como AOX, resultantes do contato da água com pesticidas, esgoto doméstico e industrial, são 10 vezes mais altos em Itajaí e Navegantes, do que no Ribeirão Alto Warnow, no interior de Indaial, referência em pesquisas pela boa qualidade de água. Em risco, fica a saúde do próprio homem (Jornal de Santa Catarina, 7 de junho de 2011).
\end{abstract}

Ainda na mesma reportagem o professor Leonardo Rorig, da Universidade Federal de Santa Catarina, afirma que "os compostos químicos encontrados nas águas do Itajaí e Navegantes são de extremos riscos por serem cancerígenos." Segundo o pesquisador os mais baixos índices de qualidade da água foram encontrados entre Blumenau e Gaspar em função da densidade populacional e da grande industrialização (Jornal de Santa Catarina, 7 de junho de 2011).

Poderíamos discutir por inúmeras páginas a poluição da bacia do rio Itajaí-Açu, entretanto esta não é a intenção que prepondera no presente trabalho. Nas próximas páginas tentaremos agregar iniciativas, medidas e ações que projetam melhorias na qualidade das águas dos rios que fazem parte da Bacia. Algumas iniciativas partem da população, outras da imprensa local e ainda através de organizações sociais ou empresariais.

Para este artigo escolhemos três projetos que consideramos importantes por trazerem denúncias e ao mesmo tempo tentarem conscientizar a população e as autoridades públicas e empresários.

\title{
Projeto Rio Vivo - Brusque
}

O projeto Rio Vivo foi uma iniciativa do Jornal O Município, que tem circulação diária nos municípios de Brusque, Botuverá, Guabiruba, Nova Trento e São João Batista. O jornal em 11 de março de 2002, adota o nome Município Dia a Dia e em março de 2017 volta ao seu nome original de $O$ Município. ${ }^{4}$

\footnotetext{
${ }^{4}$ https://omunicipio.com.br/o-municipio/ Acesso em 07 de julho de 2020.
} 
Interessante observarmos as iniciativas da imprensa escrita com suas preocupações em relação ao rio que atravessa a cidade. Em dezembro de 2004 o jornal o Município Dia a Dia, em seu editorial declara que "assumindo o seu papel de agente integrador da comunidade lançou o projeto Rio Vivo." O objetivo do projeto, segundo o periódico era, "alertar para as mudanças ambientais decorrentes da ocupação e do desenvolvimento, para através da informação, subsidiar futuras ações que levem em conta a conservação e manutenção dos recursos naturais e do meio ambiente" (Município Dia a Dia, 09.12.2004).

Desta forma, a partir do mês de dezembro de 2004 e todo o ano de 2005, o rio Itajaí-Mirim passou a ser um dos principais focos de atenção dos leitores do Jornal Município Dia-a-Dia. Os leitores passaram a fazer denúncias sobre as agressões sofridas pelo rio, como iremos ver a seguir.

No dia 12 de setembro de 2005, foi apresentado no jornal o resultado de uma pesquisa realizada entre os meses de julho e agosto do mesmo ano. A referida enquete perguntava aos leitores o seguinte: "qual presente cada um gostaria de dar para Brusque, podendo optar por uma unidade prisional avançada: um parque com área verde e dele fazer; o rio Itajaí Mirim livre da poluição; ou calçadas novas e padronizadas”. De um total de 308 pessoas que fizeram as suas escolhas, 132 votaram a favor do rio Itajaí Mirim sem poluição. Na reportagem que apresentou os resultados, o jornalista alerta que,

os principais responsáveis pela fiscalização e punição diante de atos ou pessoas que prejudicam e comprometem o nosso rio, parecem não estar muito preocupados com o problema que vem se tornando cada dia mais comum e incontrolável, como por exemplo, o despejo de substâncias e produtos químicos nos efluentes do Itajaí (O Município, 12.07.2005).

$\mathrm{Na}$ mesma reportagem fica evidente que foram feitas várias reuniões entre a comunidade, autoridades e órgãos ambientais, para buscar soluções e ações para evitar os problemas de poluição e mau cheiro. Apesar desses esforços, "crimes ambientais continuam sendo realizados na 'calada' da noite e do dia". A repórter, demonstra toda a sua insatisfação no final da reportagem quando constata que muitos são os discursos, mas poucas são ações efetivas, e conclui:

Apesar dos órgãos garantirem que estão atuando e providenciando ações mais eficazes, o Itajaí Mirim continua sendo agredido, seja por empresas que despejam produtos químicos, ou pelo lixo doméstico jogado às suas margens, somos nós quem vamos arcar com as consequências no futuro, ou melhor, nossos filhos, netos e demais descendentes (O Município, 12.07.2005). 
Apesar do jornal ter anunciado que seria para os anos de 2004 e 2005 se observa que no decorrer de outros anos adota a mesma postura de defesa do rio. Segundo notícia publicada no dia 01 de setembro de 2006, o leito do rio Itajaí-Mirim "foi manchado novamente na manhã de ontem." $\quad$ No dia 4 de janeiro de 2010, a comunidade de bairro, se mobiliza e denuncia "uma espuma branca no canal do bairro Santa Rita". Segundo a senhora Inês Raiser "que mora no local há 30 anos, afirma que tem se preocupado com uma espuma branca aparece com frequência em um canal que fíca no fim da rua." A moradora afirma "Quando não é a espuma, é água verde, vermelha, azul ou ainda com mau cheiro" (O Município 06.01.2010). Ainda na mesma reportagem a senhora Albina Montibeller, afirma que "por diversas vezes tentou vender a residência, mas a questão do cheiro forte e o alagamento tem gerado empecilhos" (O Município 06.01.2010). As denúncias continuaram nos meses subsequentes e coincidentemente no mesmo bairro, pois

uma coloração escura, com presença de cheiro forte. No local existem tubulações que devem despejar os líquidos das tinturarias, lavanderias e estamparias. Mas estes teoricamente, não devem ter coloração e tampouco cor. Por isso quando há alteração na paisagem normal do local, há indícios de poluição e a população denuncia (O Município 04.03.2010).

Ao que tudo indica, a situação não teve grandes melhoras nos anos subsequentes, e o jornal continuou com suas denúncias. No dia 05 de julho de 2012, sob a manchete "Efluentes continuam sendo despejados no Itajaí-Mirim", o repórter afirma que,

muita espuma e cheiro forte de lixo e produtos químicos. Assim estava a água do rio Itajaí-Mirim na manhã de ontem por volta das $10 \mathrm{~h} 30,(.$.$) A água escura e com forte$ cheiro espantou até os peixes, segundo o que contou um cidadão que estava na beira do rio e que tinha desistido de pescar. Moradores da região também afirmaram que os despejos acontecem constantemente (O Município, 05.12.2012).

Diante destes fatos pode ser admitido que este tipo de atuação faz parte do papel da imprensa, mas poucos são os periódicos do Estado de Santa Catarina que abordam constantemente problemas ambientais, que reclamam e exigem soluções. Também é possível hipotetizar que o referido projeto obteve resultado com base no depoimento de José Carlos Gonzaga, sobre o Rio Itajaí-Mirim. Em reportagem do Jornal O Município, de 04 de outubro de 2018, o jovem de 26 anos relata as experiências às margens do rio. 
Nas horas de folga ele costuma pescar. Já pescou em vários pontos do rio . "Atualmente seu ponto preferido é nas proximidades da ponte do Trabalhador, no Bairro Santa Rita." Ele também comenta, que a poluição é uma presença constante em suas pescarias. Pode se observar que o depoente se refere ao mesmo bairro que recebeu várias denúncias da população (O Município, 04.10.2018).

\section{Projeto Piava}

Diferentemente do Projeto Rio Vivo da cidade de Brusque, que consistia mais em atividades jornalísticas de denúncias e cobranças, o projeto Piava pode ser considerado institucional. O início se deu no ano de 2004 quando a Fundação Agência de Água do Vale do Itajaí, com sede na cidade de Blumenau, submeteu o Projeto PIAVA, para captação de recursos junto ao Programa Petrobras Ambiental. No Termo de Referência da Fundação Agência de Água do Vale do Itajaí- Fundação Piava, de 2017 temos o seguinte histórico do Projeto PIAVA:

O Projeto PIAVA (fase 1) tinha por objetivo geral o fortalecimento do processo participativo da gestão de recursos hídricos e o fomento de ações de reversão da degradação das pequenas bacias hidrográficas, por meio de ações educativas e de recuperação ambiental. O Projeto iniciou em fevereiro de 2005 e foi concluído em outubro de 2007. Em razão dos excelentes resultados do projeto, a Fundação submeteu nova proposta ao Edital do Programa Petrobras Ambiental em 2007 e foi agraciada novamente com recursos para dar continuidade ao Projeto PIAVA (fase 2), que iniciou em abril de 2008 e foi concluído em agosto de 2010. Nesse mesmo ano, após revisão do seu estatuto, a Fundação Agência de Água do Vale do Itajaí passou a adotar o nome fantasia de "Fundação Piava". Em 2016, após nova alteração estatutária, passou a ter como área de atuação, não apenas a Região Hidrográfica do Vale do Itajá́, mas todo o território do Estado de Santa Catarina (Termo de Referência, 2017).

De acordo com Beate Frank, diretora da Fundação Agência de Água do Vale do Itajaí, o objetivo central "foi inicialmente construir e depois consolidar e implementar uma política de proteção da água nos municípios da Bacia do Itajaí, culminando com a aprovação do plano de recursos hídricos da bacia” (FRANK, 2010: 127).

E os objetivos específicos e as atividades foram assim descritas:

1) Possibilitar a formação e a integração da equipe técnica, por meio da realização de oficinas públicas sobre temas correlatos à gestão participativa de recursos hídricos, de encontros para a integração e capacitação da equipe e coordenação das atividades da "Semana da Água";

2) Fomentar as ações educativas através da formação continuada dos diversos atores, por meio do acompanhamento das atividades educativas, edição de material didático- pedagógico para educação formal e não formal, formação de professores e 
lideranças, formação de profissionais da saúde em educação ambiental e fortalecimento da Reabri - Rede de Educação Ambiental da Bacia do rio Itajaí;

3) Potencializar a capacidade de atuação dos órgãos municipais de meio ambiente, visando à construção de políticas públicas de proteção da água nos municípios e sua integração no processo de gerenciamento da bacia hidrográfica;

4) Consolidar a recuperação e a preservação em áreas de nascentes e matas ciliares, por meio da criação e implementação de políticas públicas municipais de recuperação destes ambientes;

5) Desenvolver e promover a aplicação dos instrumentos da Política Nacional de Recursos Hídricos, vinculados pelo Plano de Recursos Hídricos;

6) Promover a consolidação dos organismos de gestão de recursos hídricos da bacia do Itajaí, por meio de uma crescente articulação institucional com atores estratégicos e mediante a criação de mecanismos de sustentação financeira (FRANK, 2010: 127128)

Nos objetivos fica claro que os quatro primeiros estão relacionados com a educação ambiental. Educação esta voltada a educadores, técnicos, gestores e também usuários de água. As atividades consistiram em cursos com objetivos específicos de acordo com o público alvo. Para os educadores que iriam atuar nas escolas foram trabalhados conceitos e conteúdos associados à gestão da bacia hidrográfica, destacando também a importância do desenvolvimento de projetos educativos, com ênfase à proteção da água. Os cursos voltados a técnicos e educadores tinham como objetivos a ampliação da compreensão dos fenômenos associados aos ambientes fluviais e as práticas para a recuperação dos mesmos e o estímulo para o desenvolvimento de projetos de recuperação da mata ciliar e outras atividades. Em relação às oficinas, reuniões e cursos que abrangiam um número maior de diferentes profissionais como gestores técnicos e educadores os objetivos consistiam em ampliar a compreensão do papel da gestão ambiental municipal; fomentar a adoção de políticas municipais e a criação e/ou o fortalecimento da estrutura de gestão ambiental municipal. Além de todos os cursos e oficinas acima descritos houve vários eventos onde também faziam parte os usuários de água para envolvê-los no "desenvolvimento dos instrumentos de gestão de recursos hídricos, inerentes à formulação do plano de recursos hídricos" (FRANK, 2010: 129).

Além das atividades acima mencionadas também houve a geração de produtos e atividades nas escolas e comunidades. A análise efetuada revelou que o principal produto do projeto Piava foi a organização de um livro composto por quatro áreas temáticas: 1- águas turbulentas; 2 - movimento das águas; 3 - caminho das águas; 4 magia das águas. A área temática "Águas turbulentas" destaca as cheias do rio Itajaí e a partir delas pontuar o início da mobilização da população da bacia em busca de uma solução local para controle e prevenção das enchentes. Culminado com a atuação do 
Comitê do Itajaí e o Projeto Piava. O livro pode ser acessado em: https://issuu.com/renatorizzaro/docs/piava_completo

\section{Rio Itajaí Pede Nossa Ajuda}

O Projeto Rio Itajaí Pede Nossa Ajuda, de acordo com o Boletim Técnico n. 4 surge,

com a proposta de auxiliar na mudança desta triste realidade de degradação do rio Itajaí, o Consórcio Empresarial Salto Pilão (CESAP), permissionário da Usina Salto Pilão, realizou em 2013, a campanha de conscientização e de educação ambiental denominada "Rio Itajaí-Açu pede nossa ajuda" que visa sensibilizar a comunidade regional para uma mudança, possível, de atitude em relação à conservação dos recursos hídricos, com ênfase para o Rio Itajaí (Boletim Técnico n.4, 2014: 16).

A campanha $O$ Rio Itajai Pede Nossa Ajuda, realizada pelo Consórcio Empresarial Salto Pilão (CESAP) em municípios do Alto Vale desde 2013, tem continuidade com ações junto a estudantes do ensino fundamental, atividades com professores, mobilização de agricultores e comunidade em geral com o objetivo de buscar a conscientização regional sobre o quadro de poluição do rio Itajaí, incentivando ações de preservação.

O CESAP busca com a campanha, reduzir ainda mais a quantidade do lixo que é produzido nos lares e que, grande parte acaba descartado nos rios da região, além de contribuir para despertar a necessidade de recuperação e preservação do rio, atuando em ações que envolvam escolas, entidades e comunidades, de forma a fazer do rio um bem comum, que a todos compete preservar e defender.

\section{Segundo o Boletim Técnico n.4,}

Atribuir a solução de todos os problemas ambientais somente à educação não é aconselhável. A solução certamente passa pela educação, mas também pela legislação, fiscalização, meios de comunicação, movimentos sociais e ambientais e setor produtivo. Ou seja, por toda a coletividade (Boletim Técnico n.4, 2014: 16).

As ações de cunho socioambiental envolvem mutirões de limpeza, com mobilização da sociedade, palestras em escolas e entidades, distribuição de material informativo para moradores ribeirinhos do rio Itajaí-Açu, assim como para entidades representativas, lideranças, autoridades políticas, imprensa e comunidade em geral. A campanha ainda apresentou vários materiais de suporte como um vídeo documentário, cartilha Cuidando do nosso planeta, camisetas, folders, placas, entre outros. 
As atividades mais relevantes, no nosso entendimento, dentro deste projeto foram as de educação ambiental nos municípios envolvidos. Pois de acordo com os responsáveis pela CESAP, “Como a educação ambiental é um tema já abordado em boa parte das escolas e vem ganhando espaço em outras instituições de ensino, os materiais da campanha deram suporte para o desenvolvimento de atividades pedagógicas relacionadas ao meio ambiente" (Boletim Técnico n. 4, 2014: 16).

\section{Considerações finais}

Apresentamos e analisamos três projetos no presente texto. O primeiro, Projeto Rio Vivo - Brusque, iniciativa de um jornal local/regional com sede em Brusque, onde as principais atividades consistiam em denúncias, cobranças e reportagens sobre a poluição do rio e riachos da região. É relevante observar a existência de cobranças diretas endereçadas às autoridades municipais e estaduais, para que estas tomassem medidas para o cumprimento da legislação por parte dos proprietários das indústrias poluidoras. O fato de colocarem a população para controlar de forma mesmo que indireta se constitui em educação ambiental, onde gradativamente o rio se transformasse novamente em um ser vivo para o lazer da comunidade. O Projeto PIAVA, é um modelo bem distinto do anterior, pois se constitui em um projeto institucional, ligado a setores educacionais como a Universidade Regional de Blumenau e ao comitê da Bacia do Itajaí, que teve recursos financeiros da Petrobras para executar as ações propostas por um período longo. De acordo como uma das idealizadoras a proposta foi construir, consolidar e implementar uma política de proteção da água nos municípios da Bacia do Itajaí, culminando com a aprovação do plano de recursos hídricos da bacia. (FRANK, 2010: 127). Mas, para atingirem tais objetivos o envolvimento da sociedade foi um fator importante e as ações, como pôde ser observado, tiveram como um dos principais motes a educação ambiental através da realização de cursos, oficinas, palestras voltadas a educadores técnicos, gestores e usuários de água.

Por sua vez, o projeto Rio Itajai Pede Nossa Ajuda foi instituído pelo Consórcio Empresarial Salto Pilão, responsável pela barragem da Usina Salto do Pilão. Este projeto se diferencia dos dois anteriores, por ter à sua frente o setor empresarial disponibilizando recursos para execução das ações previstas no projeto. Estas ações estavam voltadas, principalmente, para a educação ambiental onde o público alvo, em 
destaque, eram os estudantes. Como um dos resultados pode ser destacado que mais de 20.000 pessoas estiveram diretamente envolvidas com atividades de escolas da região. Este projeto teve vários mutirões para limpeza do rio, com amplo envolvimento comunitário e mobilização de equipamentos.

Por fim, este foi um exercício bastante desafiador pois juntar três iniciativas muito distintas entre si, mas que tinham entre seus objetivos dar "voz ao rio" para manter os rios da Bacia do Itajaí vivos, livres de poluição. Estas iniciativas deixaram claro que as respostas da comunidade tendo incentivos se integram. Sem dúvidas as metas propostas pelos diferentes projetos não foram atingidas de forma completa, pois nem sempre os esforços resultam em resultados concretos. Entretanto, além de avanços obtidos, também servem de exemplo para que surjam outras iniciativas e estudos sobre esta temática tão importante que é a preservação da água.

\section{REFERÊNCIAS}

AVILA, Maria Roseli Rossi; MATTEDI, Marcos Antonio. Desastre e território: a produção da vulnerabilidade a desastres na cidade de Blumenau/SC. urbe, Rev. Bras. Gest. Urbana [online]. 2017, vol.9, n.2 [cited 2020-08-26], pp.187-202. Available from: $\quad<$ http://www.scielo.br/scielo.php?script=sci_arttext\&pid=S217533692017000200187\&lng=en\&nrm=iso>. $\quad$ Epub Mar 09, 2017. ISSN 21753369. http://dx.doi.org/10.1590/2175-3369.009.002.ao03.

BOLETIM Técnico n. 4. O Rio Itajaí pede nossa ajuda. Apiúna: CESAP, 2014.

FABICIACK, Jair; NAU, Reginaldo Otto. Águas do Itajaí: uma visão dos usos do maior rio catarinense. Trabalho do curso de Especialização em Educação e Gestão da Uniasselvi, 2012. Cedido pelos autores. 
FRANK, Beate. Promoção da gestão de recursos hídricos em Bacia Hidrográfica: aprendizagem do Projeto PIAVA. Rev. eletrônica Mestr. Educ. Ambient. ISSN 15171256, v. especial, setembro de 2010 .

FRANK B.; SEVEGNANI, L. Desastre de 2008 no Vale do Itajaí: água, gente e política. Blumenau: Agência de Água do vale do Itajaí, 2009.

O MUNICÍPIO (Brusque SC) 2004 a 2018 -Disponível na Hemeroteca Nacional.

MATTEDI, M.A.: FRANK B.; SEVEGNANI L.; BOHN, N. O desastre se tornou rotina... In: Desastre de 2008 no Vale do Itajaí: água, gente e política. Blumenau: Agência de Água do vale do Itajaí, 2009.

MENEZES, Elaine Cristina de Oliveira. Industrialização e meio ambiente no Estado de Santa Catarina. Estudo de caso sobre a evolução e os impactos socioambientais do segmento têxtil-vestuarista na microrregião do Alto Vale do Itajaí. Tese de Doutorado. Programa de Pós-graduação em Sociologia Política. Universidade Federal de Santa Catarina, 2009.

PAULA, Simoni M.; ESPINDOLA, Marcos A.; NODARI, Eunice S. O crescimento urbano e as enchentes em Blumenau (SC). Revista do Arquivo Geral da Cidade do Rio de Janeiro, v.8, p. 201-212, 2014.

SANTA CATARINA em Números: Macrorregião Vale do Itajaí/Sebrae/SC. Florianópolis: Sebrae/SC, 2013. 140p.

SILVA, Roberto Antonio Capiotti da. Águas de Novembro Estudo antropológico sobre memória e vitimização de grupos sociais citadinos e ação da Defesa Civil na experiência de calamidade pública por desastre ambiental (Blumenau, Brasil). Tese de Doutorado. Programa de Pós-graduação em Antropologia Social. Universidade Federal do Rio Grande do Sul, 2013. 
TERMO de Referência. Fundação Agência de Água do Vale do Itajaí - Fundação Piava. Blumenau, 2017.

Agradecimentos a Julia Mai Velasco e Laianny C. G. Terreri bolsistas de Iniciação Científica/CNPq do Curso de História da UFSC pela coleta de fontes. E ao CNPq pela concessão do auxílio financeiro (projeto 426478/2018-5) e a Bolsa Pq.

Recebido: 30/08/2020

Aprovado: $08 / 12 / 2020$ 